\title{
Psychometric Properties of Remote Teaching Efficacy Scale in Employed Filipino Teachers during COVID-19 Crisis
}

\author{
Michael B. Cahapay ${ }^{1 *}$, Thalia Carreon ${ }^{2}$, Kenneth Garcia ${ }^{3}$, Erwin Rotas ${ }^{4}$, Romina Amador ${ }^{5}$, Jeorge Louie Anoba ${ }^{6}$
}

\author{
${ }^{1}$ Mindanao State University, PHILIPPINES \\ ${ }^{2}$ Balite Elementary School, PHILIPPINES \\ ${ }^{3}$ Romana C. Acharon Central Elementary School, PHILIPPINES \\ ${ }^{4}$ Department of Education, General Santos City, PHILIPPINES \\ ${ }^{5}$ Severo T. Inong Elementary School, PHILIPPINES \\ ${ }^{6}$ Sto. Niño Elementary School, PHILIPPINES \\ *Corresponding Author: mbcahapay@up.edu.ph
}

Citation: Cahapay, M. B., Carreon, T., Garcia, K., Rotas, E., Amador, R., \& Anoba, J. L. (2022). Psychometric Properties of Remote Teaching Efficacy Scale in Employed Filipino Teachers during COVID-19 Crisis. Journal of Digital Educational Technology, 2(1), ep2202. https://doi.org/10.21601/jdet/11435

\section{ARTICLE INFO}

Received: 1 Oct. 2021

Accepted: 17 Nov. 2021

\begin{abstract}
This paper describes the level of remote teaching efficacy of teachers amid the COVID-19 crisis and assesses the psychometric properties of the proposed Remote Teaching Efficacy (RTE) Scale. A 10-item scale originally used in the context of online teaching was modified to suit the context of the current massive migration to emergency remote teaching. A sample of $1,061 \mathrm{~K}$ to 12 employed Filipino teachers were surveyed. The items of the scale were subjected to tests of internal consistency and factor analysis. The result showed that, despite the global crisis affecting the educational system, the teachers have a high level of remote teaching efficacy. On the other hand, RTE Scale demonstrated acceptable indices of corrected item-total correlations between .73 and .82 . A high overall Cronbach's alpha at .95 was also sought, supported by excellent factor loadings between .79 and .84 . Thus, this paper concludes that RTE Scale is a reliable and valid scale that can be used to measure the remote teaching efficacy of teachers.
\end{abstract}

Keywords: psychometric properties, remote teaching efficacy, COVID-19, Philippines

\section{INTRODUCTION}

The continuing existence of COVID-19 until the present was rarely anticipated. As a consequence, due to the unpreparedness of most countries for this situation, there have been many difficulties in overcoming and recovering from the enormously damaging effects of the crisis. Some authorities claim that the world is now experiencing the most challenging crisis since World War II and the Great Depression (Blair, 2020). As a dangerous and contagious disease causing deadly respiratory illnesses, COVID-19 has infected 241,886,635 people, including 4,919,755 deaths as of 20 October 2021 (World Health Organization, 2021).

With the multidimensional impacts of COVID-19 on the different aspects of the community, the education sector is neither spared (United Nations, 2020). Many countries have resorted to remote teaching (Cahapay, 2020). Remote teaching can be described as an alternative modality when boundaries between the teachers and the learners have to be set, disabling face-to-face interactions. This definition has been carefully carried in the context of emergency remote teaching of the present COVID-19 crisis. Thus, remote teaching became an emergency response, enabling educational leaders for modes that would be suitable to the current needs (Hodges et al., 2020). These modes include online and offline in which synchronous and asynchronous learning may take place (Ferri et al., 2020).

The Philippines also adopted remote teaching to cope with the current situation. As a developing country, however, most of the teaching process does not occur online. Considering the structural resources of most schools in the country, the Department of Education (2020) prescribed the use of other offline remote learning modalities in its learning continuity plan (Cahapay, 2021). Of these offline remote learning modalities, modular learning has become the major offline remote learning modality in the country with an estimated 13 million students engaged in this modality this school year (Magsambol, 2020). Other offline remote learning modalities adopted in the different schools around the country are radioand television- based instruction, homeschooling, and the use of digital modules saved in flash drives, $\mathrm{CD}$ tapes, and OTGs (Codamon, 2020). 
As remote teaching is becoming the new mode of instructional implementation, one important aspect to carefully examine is the efficacy of the teachers in this modality (Beteille, 2020). Bandura (1994) pioneered the cognitive concept of efficacy, a notion of a person about his or her ability to accomplish a task. The sudden transfer to remote teaching has sparked many challenges, such as difficulties in the delivery of the learning materials and assessment of student performance (Cahapay \& Labrador, 2021), which influence the efficacy of teachers (Dizon, 2020). Aside from these challenges, teachers also experience anxiety due to economic uncertainty, safety issues, and societal pressure amid the current crisis (Beteille, 2020). The efficacy of the teachers may vary after the sudden change to remote teaching (Rogers-Haverback, 2020). Thus, it is a vital act to support the teachers with the needed assistance to be able to successfully implement educational programs during COVID-19 (Dela Cruz, 2020).

Researchers have emphasized the importance of assessing the teaching efficacy of the teachers (e.g., Barni et al. 2019; Daniel, 2020; Di Pietro, et al. 2020; Kraft et al. 2020; Larsen \& Samdal, 2012; Rice, 2003). However, other than the general teaching efficacy, most instruments were developed in the context of online teaching (e.g., Artino \& McCoach, 2008; Corry \& Stella, 2018; Gosselin, 2016; Horvitz et al. 2014; Lazar et al. 2020; Tschannen-Moran \& Woolfolk, 2001; Zimmerman \& Kulikowich, 2016). It should be noted that remote teaching, as emphasized by Hodges et al. (2020) and considering also the context of most Philippine schools, is an appropriate term to be used in emergency cases rather than online teaching. As far as this study is concerned, no scholarly works have been initiated to develop a reliable and valid tool to assess the efficacy of teachers in the context of remote teaching.

It is important to develop assessment tools for various aspects in particular groups, such as the remote teaching efficacy of the Filipino teachers, for appropriate interventions (Cortez et al., 2020). As schools navigate the crisis brought by the COVID-19 crisis, there is a need to evaluate the efficacy of teachers in remote teaching to provide responsive measures. Empirical evidence of the remote teaching efficacy of the teachers generated from a reliable and valid tool will help the educational leaders create relevant responses, thus navigating ways towards the success of the implementation of remote teaching.

Hence, considering the circumstances above, the researchers aimed to describe the level of remote teaching efficacy and assess the psychometric properties of the proposed Remote Teaching Efficacy (RTE) Scale in the teachers.

\section{METHODS}

This section outlines the procedure for establishing the psychometric properties of the proposed RTE Scale in professional Filipino teachers. This procedure is elaborated as follows.

\section{Samples}

The study involved 1,061 Filipino $\mathrm{K}$ to 12 teachers in Mindanao, Philippines. They were recruited through a combination of purposive and snowball sampling techniques where researchers started with a small number of known teachers, mostly from their professional circles. Then, they asked the teachers who initially participated to identify other teachers until the present sample size was found (Chan, 2020). The respondents were chosen regardless of gender, age, religion, position, educational attainment, and socioeconomic status.

Specifically, as per gender, $79.8 \%$ females comprise the majority of the target respondents and $20.2 \%$ are male teachers. In terms of age, $11 \%$ teachers belong to 24 years old and below bracket; $44.7 \%$ were ranging from $25-34$ years old teachers; nearly one-fourth or $24.6 \%$ were between $35-44$ years old; $15.2 \%$ teachers were amongst $45-54$ years old; and 55-64 years old teachers (4.5\%) provided the least number of responses.

\section{Instrument}

The instrument used was adapted from the 10-item scale of Lazar et al. (2020) based on various sources and used to assess the online teaching efficacy of teachers amid the COVID-19 situation. The original scale has very good reliability scores in terms of internal consistency $(\alpha=0.93)$ and strong factor loadings ranging from .63-.91.

Particularly, in this study, the research team modified items $1,2,3$, and 7 to suit the context of remote teaching and learning. On the other hand, items $4,5,6,8,9$, and 10 were retained as they were found relevant to measure the level of efficacy of teachers in remote teaching. The final version of the scale was framed in a five-point Likert-type scale, ranging from 1 being "Strongly Disagree" to 5 being "Strongly Agree."

\section{Data Collection}

The data collection for this study was conducted from 25 January to 31 January 2021, through an online survey using Google link. The survey occurred in two stages. The first stage was the introduction of the study and obtaining the consent of the target respondents. The researchers sought to explain the purpose of the study and the voluntary role of the respondents in providing the needed data. They were assured that the confidentiality of the information will be observed during the process.

The second stage was the conduct of the main questionnaire. It started to ask for the following specific personal information of the respondents: age, gender, rank, civil status, monthly income, educational attainment, and teaching experience. Then, it presented the 10-item RTE Scale. After accessing and answering, their responses were automatically recorded. Finally, the researchers generated the data.

\section{Data Analysis}

Several phases of analysis were conducted to determine the psychometric properties of the scale under study. The ten-item RTE Scale was first subjected to a reliability test using Cronbach's alpha. This process offers evidence that the items 
have internal consistency (Bhattacherjee, 2012). The acceptable level of Cronbach's alpha is .70 for a scale to be considered reliable as recommended by Taber (2018). This measure will assure that the items in the RTE Scale are interconnected and are measuring the same construct.

Consequently, the items were further subjected to factor analysis to examine the construct validity (Mukherjee et al., 2018). Since the researchers aimed to confirm if the items support a hypothesized construct from a previous scale developed in a similar context and sample, confirmatory factor analysis was used (Knekta et al., 2019). In this regard, items with factor loadings lower than .40 would be removed from the final version of the RTE Scale based on the criterion of Kuan et al. (2019). It should be noted that to achieve good psychometric characteristics, high factor loadings must be sought because they indicate good construct validity.

Aside from the above tests, descriptive statistics provided the frequency count, weighted mean, and standard deviation for the initial analysis of the RTE Scale items and described the level of remote teaching efficacy of the teachers. All tests in this study were performed using the IBM Statistical Package for Social Science Version 17.

\section{RESULTS AND DISCUSSION}

\section{Remote Teaching Efficacy of Teachers}

This paper initially surveyed the level of efficacy of teachers in remote teaching using the adapted 10-item RTE Scale. Table 1 shows the results.

The teachers agree that they can help their students to use remote learning environments effectively $(\mathrm{M}=3.90, \mathrm{SD}=.88)$; can design lessons so that they can be used in remote learning environments $(\mathrm{M}=3.90, \mathrm{SD}=.87)$; are able to recommend study materials enriched with open educational resources $(\mathrm{M}=3.88$, $\mathrm{SD}=.87)$; constructively address the challenge of remote teaching $(\mathrm{M}=3.86, \mathrm{SD}=.84)$; and can use technologies which allow them to interact remotely $(\mathrm{M}=3.82, \mathrm{SD}=.99)$.

Furthermore, the teachers can use tools for remote teaching, as well as all their colleagues $(\mathrm{M}=3.78, \mathrm{SD}=.88)$; believe their digital skills allow me to use technologies suitable for remote teaching $(\mathrm{M}=3.76, \mathrm{SD}=.94)$; can use online tools to assess the knowledge of their students $(\mathrm{M}=3.71, \mathrm{SD}=.98)$; can use appropriate digital technologies that allow them to interact with students $(\mathrm{M}=3.71, \mathrm{SD}=.97)$; and adapt quickly to the requests of students when teaching remotely $(\mathrm{M}=3.71$, $\mathrm{SD}=.90)$.

Overall, the teachers agree as regards their favorable perception of their efficacy in remote teaching $(M=3.80)$. This depicts the high level of confidence of Filipino teachers in remote teaching. It can be noted that all the items have a close gap of mean values. This means that the respondents agree to all the items implying favorable confidence in remote teaching. Kazu (2014) underscored that teachers that regarded themselves as having high efficacy results in them seeing themselves as efficient teachers. This result interestingly agrees with the recent study by Lazar et. al (2020) and most related studies conducted in the past (e.g., Black, 2019; Horvitz et al., 2015; Robinia, 2008).

\section{Reliability of RTE Scale}

The items of the RTE Scale were first subjected to reliability tests to identify the level of internal consistency of the scale. Table 2 shows the results.

The initial result of computation showed acceptable corrected item-total correlation varying between .73 and .82 . The result further indicated that the overall Cronbach's alpha coefficient of the scale did not significantly improve if an item is deleted ranging within .94. The overall Cronbach's alpha coefficient of the entire RTE Scale, with its adapted 10 items, was found to be .95 . These results suggest that the adapted 10item RTE Scale is an instrument with a high internal consistency that can be used to assess the efficacy of Filipino teachers in the context of remote teaching.

The reliability result of this study is comparable to the original tool and other similar ones. The reliability index of this scale used in the sample of Filipino teachers $(\alpha=.95)$, which is slightly higher than the original efficacy scale in the context of online teaching ( $\alpha=.93$ ) by Lazar et al. (2020) and the remote teaching efficacy scale $(\alpha=.93)$ by Cardullo et al. (2020). When compared to extant online teaching efficacy scales tested in the past, the RTE scale has a higher reliability index than that $(\alpha=.93)$ of Robinia and Anderson (2010); but is equal to that of Gosselin (2009), where $\alpha=.95$. Nevertheless, these scales and the proposed RTE scale have excellent reliability values because they are above the 0.70 cut off as recommended by Taber (2018).

\section{Validity of RTE Scale}

Moreover, the items of the RTE Scale were subjected to factor analysis to determine their construct validity. Table 3 shows the result.

Table 1. Remote teaching efficacy of teachers

\begin{tabular}{|c|c|c|c|}
\hline Item & Mean & SD & Description \\
\hline I can help my students to use remote learning environments effectively & 3.90 & .88 & Agree \\
\hline I can use technologies which allow me to interact remotely & 3.82 & .99 & Agree \\
\hline I can design lessons so that they can be used in remote learning environments & 3.90 & .87 & Agree \\
\hline I am able to recommend study materials enriched with open educational resources & 3.88 & .87 & Agree \\
\hline I can use online tools to assess the knowledge of my students & 3.71 & .98 & Agree \\
\hline My digital skills allow me to use technologies suitable for remote teaching & 3.76 & .94 & Agree \\
\hline I can use appropriate digital technologies that allow me to interact with students & 3.71 & .97 & Agree \\
\hline I adapt quickly to the requests of students when teaching remotely & 3.71 & .90 & Agree \\
\hline I can use tools for remote teaching, as well as all my colleagues & 3.78 & .88 & Agree \\
\hline I constructively address the challenge of remote teaching & 3.86 & .84 & Agree \\
\hline Overall & 3.81 & .91 & Agree \\
\hline
\end{tabular}


Table 2. Reliability of RTE scale

\begin{tabular}{ccc}
\hline \multicolumn{1}{c}{ Item } & $\begin{array}{c}\text { Corrected item-total } \\
\text { correlation }\end{array}$ & $\begin{array}{c}\text { Cronbach's Alpha if } \\
\text { item deleted }\end{array}$ \\
\hline I can help my students to use remote learning environments effectively & .73 & .94 \\
\hline I can use technologies which allow me to interact remotely & .76 & .94 \\
\hline I can design lessons so that they can be used in remote learning environments & .78 & .94 \\
\hline I am able to recommend study materials enriched with open educational resources & .76 & .94 \\
\hline I can use online tools to assess the knowledge of my students & .80 & .94 \\
\hline My digital skills allow me to use technologies suitable for remote teaching & .82 & .94 \\
\hline I can use appropriate digital technologies that allow me to interact with students & .82 & .94 \\
\hline I adapt quickly to the requests of students when teaching remotely & .94 \\
\hline I can use tools for remote teaching, as well as all my colleagues & .90 \\
\hline I constructively address the challenge of remote teaching & .79 & .94 \\
\hline Overall Cronbach's alpha & .77 & .94 \\
\hline
\end{tabular}

Table 3. Validity of RTE scale

\begin{tabular}{cc}
\hline Item & Factor loading \\
\hline I can help my students to use remote learning environments effectively & .79 \\
\hline I can use technologies which allow me to interact remotely & .80 \\
\hline I can design lessons so that they can be used in remote learning environments & .82 \\
\hline I am able to recommend study materials enriched with open educational resources & .80 \\
\hline I can use online tools to assess the knowledge of my students & .84 \\
\hline My digital skills allow me to use technologies suitable for remote teaching & .86 \\
\hline I can use appropriate digital technologies that allow me to interact with students & .86 \\
\hline I adapt quickly to the requests of students when teaching remotely & .84 \\
\hline I can use tools for remote teaching, as well as all my colleagues & .84 \\
\hline I constructively address the challenge of remote teaching & .81 \\
\hline
\end{tabular}

A preliminary measure for factor analysis demonstrated the adequacy of sampling used for the scale with KaiserMeyer-Olkin value at .94 and significant Bartlett test of sphericity at .00 level. The analysis further uncovered ten components with initial eigenvalues of 0.1 and higher of which one factor satisfied comprising cumulative extraction sums of squared loadings at $68.55 \%$. The result of extraction using principal component analysis resulted in the identification of factor loadings for each item. The computed factor loadings ranged from .79 to .84 , which are way greater than the set limit. These results imply that the adapted 10-item RTE Scale is a valid tool to measure the efficacy of Filipino teachers when it comes to remote teaching.

While a question on whether efficacy is unidimensional or multidimensional (Zhou, 2016) is currently unresolved, the factor analysis of the RTE scale supports the unidimensionality of efficacy with one factor explaining $68.55 \%$ of the variability in all variances. This result agrees with that of the original scale developed by Lazar et al. (2020). Moreover, the overall result of this study indicates a strong construct validity of the RTE Scale with factor loadings between .79 and .84, which are comparable to the original version of Lazar et al. (2020) with factor loadings between .63 and .91 . All the items of the RTE Scale can be retained as they pass the .40 minimum factor loading suggested by Kuan et al. (2019).

\section{CONCLUSIONS}

This paper is mainly carried out to establish the psychometric properties of the proposed RTE Scale that can be used to accurately assess the remote teaching efficacy of Filipino teachers amid the current COVID-19 pandemic. The initial result of the paper revealed that the respondents generally display a high level of confidence in remote teaching. As evidenced by the statistical results and conforming to scale development standards, the RTE Scale demonstrated high internal consistency and excellent construct validity. Thus, this study provides confidence that RTE Scale is both a reliable and valid scale. Given the immediate need to study the impact of the crisis in education, this scale can be used to ascertain one of the possible affected teaching conditions which is the teaching efficacy of teachers in the context of remote teaching.

Author contributions: All co-authors have involved in all stages of this study while preparing the final version. They all agree with the results and conclusions.

Funding: No external funding is received for this article.

Declaration of interest: The authors declare that they have no competing interests.

Ethics approval and consent to participate: Not applicable.

Availability of data and materials: All data generated or analyzed during this study are available for sharing when appropriate request is directed to corresponding author.

\section{REFERENCES}

Artino, A. R., \& McCoach, D. B. (2008). Development and initial validation of the online learning value and selfefficacy scale. Journal of Educational Computing Research, 38(3), 279-303. https://doi.org/10.2190/EC.38.3.c

Bandura, A. (1994). Self-efficacy. In V. S. Ramachaudran (Ed.), Encyclopedia of human behavior (pp. 71-81). Academic Press. 
Barni, D., Danioni, F., \& Benevene, P. (2019). Teachers' selfefficacy: The role of personal values and motivations for teaching. Frontiers in Psychology, 10, 1645. https://doi.org/10.3389/fpsyg.2019.01645

Beteille, T. (2020). Supporting teachers during the COVID-19 (coronavirus) pandemic. World Bank Blogs. https://blogs.worldbank.org/education/supportingteachers-during-covid-19-coronavirus-pandemic

Bhattacherjee, A. (2012). Social science research: Principles, methods, and practices. Textbooks Collection 3.

Black, M. R. (2019). A comparative analysis of teacher efficacy scores of online business faculty based on educational background [Doctoral dissertation, Liberty University].

Blair, T. (2020). The world was not prepared for COVID-19. We should learn the lessons and change. Institute for Global Change. https://institute.global/tony-blair/world-was-not -prepared-covid-19-we-should-learn-lessons-and-change

Cahapay, M. B. (2020). A reconceptualization of learning space as schools reopen amid and after COVID-19 pandemic. Asian Journal of Distance Education, 15(1), 269-276. https://doi.org/10.5281/zenodo.3892969

Cahapay, M. B. (2021). Philippine basic education learning continuity plan: Creating space for indigenous peoples toward inclusive post-COVID-19 education. International Journal of Pedagogical Development and Lifelong Learning, 2(1), ep2102. https://doi.org/10.30935/ijpdll/9294

Cahapay, M. B., \& Labrador, M. G. P. (2021). Experiments gone wrong? Lived experience of Filipino teachers in remote science education amid COVID-19 crisis. Asian Journal of Science Education, 3(2), 90-101.

Cardullo, V., Wang, C.-h, Burton, M., \& Dong, J. (2021). K-12 teachers' remote teaching self-efficacy during the pandemic. Journal of Research in Innovative Teaching \& Learning, 4(1), 32-45. https://doi.org/10.1108/jrit-10-20200055

Chan, J. T. (2020). Snowball sampling and sample selection in a social network. Advances in Econometrics, 61-80. https://doi.org/10.1108/s0731-905320200000042008

Corry, M., \& Stella, J. (2018). Teacher self-efficacy in online education: A review of the literature. Research in Learning Technology, 26, 2047. https://doi.org/10.25304/rlt.v26.2047

Cortez, P. A., Joseph, S. J., Das, N., Bhandari, S. S., \& Shoib, S. (2020). Tools to measure the psychological impact of the COVID-19 pandemic: What do we have in the platter? Asian Journal of Psychiatry, 53, 102371. https://doi.org/ 10.1016/j.ajp.2020.102371

Daniel, S. J. (2020). Education and the COVID-19 pandemic. Prospects 49, 91-96. https://doi.org/10.1007/s11125-02009464-3

Dela Cruz, L. I. (2020). The impact of COVID-19 on teachers' mental health: Managing psychological and emotional well-being. LearnTech Asia. https://learntechasia.com/ webinar-covid-impact-on-teachers-students-mentalhealth/
Di Pietro, G., Biagi, F., Costa, P., Karpiński Z., \& Mazza, J. (2020). The likely impact of COVID-19 on education: Reflections based on the existing literature and international datasets. EUR 30275 EN, Publications Office of the European Union, Luxembourg. https://doi.org/10.2760/ 126686

Dizon, G. (2020). Challenges vs solutions: Are 28.5 million Filipino students ready for distance learning? PhilStar Global. https://www.philstar.com/lifestyle/businesslife/2020/08/06/2033084/challenges-vs-solutions-are285-million-filipino-students-ready-distance-learning

Gosselin, K. P. (2016). Development and psychometric exploration of the online teaching self-efficacy scale. Texas Tech University Library. http://hdl.handle.net/2346/8971

Hernando-Malipot, M. (2020). Finding ways to make distance learning better. AHA! Learning Center. https:/www.ahalearningcenter.com/stories/findingways-to-make-distance-learning-better

Hodges, C., Moore, S., Lockee, B., Trust, T., \& Bond, A. (2020). The difference between emergency online teaching and online learning. Educause Review. https://er.educause.edu/ articles/2020/3/the-difference-between-emergencyremote-teaching-and-online-learning

Horvitz, B., Beach, A., Anderson, M., \& Xia, J. (2014). Examination of faculty self-efficacy related to online teaching. Innovative Higher Education, 40(4), 305-316. https://doi.org/10.1007/s10755-014-9316-1

Joaquin, J., Biana, H., \& Dacela, M. A. (2020). The Philippine higher education sector in the time of COVID-19. Frontiers in Education, 5, 576371. https://doi.org/10.3389/ feduc.2020.576371

Knekta, E., Runyon, C., \& Eddy, S. (2019). One size doesn’t fit all: Using factor analysis to gather validity evidence when using surveys in your research. CBE-Life Sciences Education, 18(1), 1-17. https://doi.org/10.1187/cbe.18-040064

Kraft, M. A., Simon, N., \& Lyon, M. A. (2020). Sustaining a sense of success: The importance of teacher working conditions during the COVID-19 pandemic. EdWorkingPaper, 20-279. https://doi.org/10.26300/35njv890

Kuan, G., Kueh, Y. C., Abdullah, N., \& Tai, E. L. M. (2019). Psychometric properties of the health-promoting lifestyle profile II: Cross-cultural validation of the Malay language version. BMC Public Health, 19, 751. https://doi.org/ 10.1186/s12889-019-7109-2

Larsen, T., \& Samdal, O. (2012). The importance of teachers' feelings of self-efficacy in developing their pupils' social and emotional learning: A Norwegian study of teachers' reactions to the Second Step program. School Psychology International 33(6), 631-645. https://doi.org/10.1177/ 0143034311412848 
Lazar, I., Panisoara, I., Panisoara, G., Chirca, R., \& Ursu, A. (2020). Motivation and continuance intention towards online instruction among teachers during the COVID-19 pandemic: The mediating effect of burnout and technostress. International Journal of Environmental Research and Public Health 17(21), 8002. https://doi.org/ 10.3390/ijerph17218002

Magsambol, B. (2020). Over 24 million Filipino students back to school during pandemic. Rappler. https://www.rappler.com/ nation/filipino-students-back-to-school-duringcoronavirus-pandemic-october-5-2020

Mukherjee, S. P., Sinha, B. K., Chattopadhyay, A. (2018). Statistical methods in social science research. Springer. https://doi.org/10.1007/978-981-13-2146-7_10

Rice, J. (2003). Understanding the effectiveness of teacher attributes. Economic Policy Institute. https://www.epi.org/ publication/books_teacher_quality_execsum_intro/

Robinia, K. A. (2008). Online teaching self-efficacy of nurse faculty teaching in public, accredited nursing programs in the State of Michigan [Doctoral dissertation, Western Michigan University].

Robinia, K. A., \& Anderson, M. L. (2010). Online teaching efficacy of nurse faculty. Journal of Professional Nursing, 26(3), 168-175. https://doi.org/10.1016/j.profnurs.2010.02. 006
Rogers-Haverback, H. (2020). Middle level teachers quarantine, teach, and increase self-efficacy beliefs: Using theory to build practice during COVID-19. Middle Grades Review, 6(2), 6.

Taber, K. S. (2018). The use of Cronbach's alpha when developing and reporting research instruments in science education. Research in Science Education, 48, 1273-1296. https://doi.org/10.1007/s11165-016-9602-2

Tschannen-Moran, M., \& Woolfolk Hoy, A. (2001). Teacher efficacy: Capturing and elusive construct. Teaching and Teacher Education, 17, 783-805. https://doi.org/10.1016/ s0742-051x(01)00036-1

United Nations. (2020). Policy belief: Education during COVID19 and beyond. https://www.un.org/development/desa/ dspd/wpcontent/uploads/sites/22/2020/08/sg_policy_brief _covid-19_and_education_august_2020.pdf

World Health Organization. (2021). WHO Coronavirus disease (COVID-19) dashboard. https://doi.org/10.46945/ bpj.10.1.03.01

Zhou, M. A. (2016). Revisit of general Sself-efficacy scale: Unior multi-dimensional? Current Psychology, 35, 427-436. https://doi.org/10.1007/s12144-015-9311-4

Zimmerman, W. A., \& Kulikowich, J. M. (2016). Online learning self-efficacy in students with and without online learning experience. American Journal of Distance Education, 30(3), 180-191. https://doi.org/10.1080/ 08923647.2016 .1193801 